\title{
Exploring the Challenges and Opportunities for Improving the Health and Wellbeing of International Students: Perspectives of Professional Staff at an Australian University
}

\author{
Danielle C. Newton \\ Institute for Health Transformation \\ Faculty of Health, Deakin University \\ Adrian J. Tomyn \\ Bupa, Melbourne, Victoria \\ School of Psychology \\ Faculty of Health, Deakin University \\ Anthony D. LaMontagne \\ Institute for Health Transformation \\ Faculty of Health, Deakin University
}

\begin{abstract}
There are growing concerns about the mental health of university students, with particular concerns for international students studying in countries with different language and culture from the country of origin. We sought to explore the challenges and opportunities for supporting and improving the health and wellbeing of international students through interviews with health and other support services staff at an Australian University.

Semi-structured interviews with a range of health and support services staff were conducted in person or by telephone in late 2018. Staff were asked about their perceptions of 1) health and wellbeing issues for international students, 2) barriers to international students accessing campus-based services for health and wellbeing concerns, and 3) strategies to improve international students' health and wellbeing. Transcribed interviews were analysed thematically.

Mental health/illness was identified as the most important health and wellbeing concern for international students. Barriers to help-seeking included fear of repercussions for coming forward, lack of problem and symptom recognition, poor understanding of health information, cultural stigma associated with counselling and language barriers. A tendency among international students to delay help-seeking until problems reached crisis-point was also identified as a concern. Suggested strategies to improve wellbeing included pre-departure education/orientation to life in Australia, the integration of health and wellbeing education with other university programs, education about confidentiality, better supporting students in how to access services, and skill building to promote social connection. Addressing the identified issues and opportunities would support international student health and wellbeing and may assist in attracting international students back to Australia post-COVID.
\end{abstract}

\section{Keywords}

International students, health care, mental health, higher education, wellbeing

\section{Background}

Students choose to undertake tertiary education outside of their home countries for many reasons including access to quality education, to acquire skills that may not be available to them in their home country, to improve language skills, or to improve employability prospects (OECD, 2018). The latest figures indicate that there are 3.5 million international and overseas students worldwide who are studying at the tertiary level in a foreign country (OECD, 2018). Students from Asia comprise the largest group of international students enrolled in tertiary education programs at all levels (1.9 million, 55\% of all international students in 2016)(OECD, 2018). Two-thirds of Asian students choose to study in one of three countries: Australia (15\%), the United Kingdom (11\%) or the United States (38\%) (OECD, 2018). 
International education is the fourth largest export for Australia, currently worth $\$ 35.2$ billion to the Australian economy (Department of Education and Training, 2019a, 2019c). Numbers of international students studying in Australia are increasing, with Australia set to surpass the UK to become the second most popular destination globally for international students (Marginson, 2018). In April 2019, there were a recorded 612,849 international students studying in Australia, a 12\% increase on the previous year (Department of Education and Training, 2019d). More than half of all international students studying in Australia come from one of five countries: China (29\%), India (15\%), Nepal (7\%), Brazil (4\%), and Vietnam (4\%) (Department of Education and Training, 2019d).

Most international students have a positive experience studying in Australia. The latest International Student Survey (ISS), funded by the Australian Government to enable benchmarking against other countries, found that $89 \%$ of the over 80,000 international students who participated in the survey were satisfied or very satisfied with their living and learning experience in Australia (Department of Education and Training, 2019b). Compared to other countries, including the USA, Canada, UK and New Zealand, international students studying in Australia report similar satisfaction with their learning experience $(88.5 \%$ versus $87.5 \%$ in other countries) and slightly higher satisfaction with living than other countries (90.4\% versus $88.4 \%$ in other countries)(Department of Education and Training, 2019b). Yet research also shows that international students experience significant challenges that may compromise their physical and emotional wellbeing. These include navigating a new and unfamiliar educational system and social environment, homesickness, culture shock, loneliness, racial discrimination, language barriers, and financial difficulties (Forbes-Mewett \& Sawyer, 2016; Hyun et al., 2007; Mori, 2000; Poyrazli et al., 2002; Sawir et al., 2008).

The mental health of university students in general has been gaining increasing research attention (Auerbach et al., 2016; Auerbach, Mortier, Bruffaerts, Alonso, Benjet, Cuijpers, Demyttenaere, Ebert, Green, Hasking, Lee, et al., 2018; Auerbach, Mortier, Bruffaerts, Alonso, Benjet, Cuijpers, Demyttenaere, Ebert, Green, Hasking, Murray, et al., 2018; Department of Education and Training, 2017; Ebert et al., 2018; Ebert et al., 2019) and has become a key focus of University Strategy in Australia via the development of the Australian University Mental Health Framework (Carlson et al., 2020). The World Health Organisation (WHO) World Mental Health International College Student (WMH-ICS) initiative conducts annual surveys of college and university students throughout the world, including Australia, and uses this information to estimate prevalence of mental disorders, adverse consequences (on the personal, social, and academic levels) of these disorders, patterns of help-seeking for these disorders, and barriers to treatment. To date, the findings have documented a high prevalence, substantial impairment and consistently low receipt of treatment for mental disorders across a growing number of colleges and countries, including Australia (Alonso et al., 2018; Auerbach, Mortier, Bruffaerts, Alonso, Benjet, Cuijpers, Demyttenaere, Ebert, Green, Hasking, Murray, et al., 2018; Cuijpers et al., 2019; Ebert et al., 2019). There is also some evidence indicating that, compared to local students, international students may experience higher rates of mental health problems. For example, one Australian study found that, compared to local students, international students reported significantly higher levels of both stress and anxiety (Redfern, 2016). Similarly, another study of Chinese-speaking international students living in Australia found that $54 \%$ of participants reported high psychological distress, specifically anxiety and/or depression measured using the K-10 (Lu et al., 2014). Lu et al. (2014) noted that the K-10 mean of Chinese-speaking international students (23.96 points) was higher (worse) than that of domestic tertiary students reported in another Australian study (20.24 points) (Ryan et al., 2010). Of the 54\% of Chinesespeaking international students reporting high levels of psychological distress, only $9 \%$ reported seeking mental health services in the last year (Lu et al., 2014).

Help-seeking, particularly for mental health problems, appears to be a particular issue for international students (Hyun et al., 2007). Indeed, a recent report arising from a Victorian Coronial investigation of the suicide of a Chinese-national student studying in Australia, reported that a lack 
of help-seeking for deteriorating mental health states was a common factor among a number of recent international student suicides in Australia (Coroners Court of Victoria, 2019). This concurs with results of a survey of both local and international students studying at a Tasmanian University that found international students were less likely than local students to seek help for mental health, relationship, alcohol or substance use problems (Skromanis et al., 2018). Moreover, over one third of all international students reported that, at some point, they had felt the need to seek professional help for a problem but chose not to do so (Skromanis et al., 2018).

Another study of international students at a Melbourne-based University found that, although $28 \%$ of students reported that they had felt they needed help from the University counselling service, only $20 \%$ of these students actually sought help from the service (Rosenthal et al., 2006). Other research has indicated that, compared to local students, international students studying in Australia may be more likely to delay help-seeking for a mental health problem until a problem reaches 'crisis point' (Forbes-Mewett \& Sawyer, 2016). Reasons for this include thinking their problem is not important/serious enough, feeling that they can manage the problem on their own, thinking services would not be able to help them, costs or transportation concerns, limited knowledge of available services, time constraints, language difficulties, and lack of knowledge concerning the symptoms of psychological distress (Forbes-Mewett \& Sawyer, 2011, 2016; Lu et al., 2014; Rosenthal et al., 2006).

In addition to mental health issues, research has also identified other health and wellbeing issues experienced by international students in Australia. These include poor perceived social support and disappointment in lack of opportunities to connect with local students and the community in general (Arkoudis et al., 2019; Ryan et al., 2016; Skromanis et al., 2018); difficulties in finding and maintaining secure and safe accommodation, particularly at the time of arrival in Australia (Ryan et al., 2016); difficulties in managing the cost of living and in finding and maintaining employment (Blackmore et al., 2017; Department of Education and Training, 2015; Gribble, 2014; Ryan et al., 2016); problems with alcohol use and gambling (Ryan et al., 2016); as well as experiences of abuse and exclusion (Rosenthal et al., 2006).

As part of a larger study including a student survey and student interviews, in this paper we sought to explore the challenges and opportunities for supporting and improving the health and wellbeing of international students through interviews with health and other support services staff at an Australian University. Through these interviews we aimed to explore staff perceptions of 1) key health and wellbeing issues for international students; 2) barriers to international students accessing campusbased services for health and wellbeing needs; and 3) strategies that might improve international students' health and wellbeing.

\section{Method}

\section{Sampling and recruitment}

Professional staff were recruited from a large Australian University with both metropolitan and regional campuses. A total of 25 professional staff from services supporting the health and wellbeing of international students were invited to take part in an interview. Staff were initially identified through a list generated by a Senior Management representative familiar with the range of student services and activities. Twelve staff were interviewed from the initial list and snowball sampling was utilised to identify a further 13 key members of staff providing health and wellbeing services to international students. The research team attempted to recruit staff members from the majority of the University services and from all campuses. Staff from the following University services were represented: medical services, residential services, counselling services, student services, English language services, disability services, as well as key faculty/executive representatives. Ethics approval was provided by the Deakin University Human Research Ethics Committee. 


\section{Data collection}

A semi-structured interview schedule was developed to explore staff perceptions of the most significant health and wellbeing concerns for international students. They were also asked about their perceptions of the barriers to international students accessing university support services and were asked to suggest strategies for improving the health and wellbeing of international students at the university. Interviews were conducted face-to-face or over the telephone and typically lasted between 45-60 minutes. All interviews were audio recorded and transcribed verbatim.

\section{Data analysis}

All transcripts were imported into NVivo for analysis. Thematic analysis of the interview data was undertaken by a primary coder (author DCN) using a progressive process of classifying, comparing, grouping and refining groups of text segments to create and then clarify the definition of categories, or themes, within the data (Skeat, 2010). To ensure inter-rater reliability, another coder (author ADL) independently coded a sub-section of interviews and cross-checked these with the findings of the primary coder. Discrepancies were discussed and a mutually agreeable interpretation was reached.

\section{Results}

Findings are presented under the three broad areas addressed in the interviews with subheadings for each theme identified as part of the analysis. Themes are presented in order of the strength of their representation within the data.

\section{What are the most significant health and wellbeing concerns for international students?}

\section{Mental health}

Mental health concerns including stress, depression, anxiety, and complex psychiatric conditions were, by far, the most commonly mentioned concerns.

The biggest issues that we have is around mental health, rather than physical health issues.

We certainly do see a number of international students with depression and anxiety, adjustment issues.

So I think for international students it would be anxiety and depression.

My understanding is that the top issue is probably mental health. Breaking that downstress; depression; anxiety, those seem to be the bigger issues.

International students struggling with pre-existing mental health conditions were seen to be a particular issue. Without the support of their usual networks, these students can rapidly deteriorate.

Often, international students, they have mental health issues prior to arriving, but on arrival and then sort of being isolated from family and support networks, they tend to, you know, the symptoms and signs can sort of get worse quite quickly as they've moved out, you know, away from their natural environment of home and family and friends. 
Often these students have never received a formal diagnosis or treatment in their home country despite having symptoms or behaviours of concern. This situation is particularly challenging for university health and wellbeing services because they often have very little information about a student's history.

Unfortunately many students come to Australia with undiagnosed mental health conditions, problems, whatever you want to call, and some with a diagnosis that aren't being - that hadn't been well treated back in their home country, or had been well treated and they don't have hand over notes to provide to doctors or psychiatrists or psychologists in Australia.

Sometimes students will stop taking their prescribed medications before coming to Australia, causing symptoms to emerge and behaviours to escalate.

I've had quite a few international students this year, who have been put in psychiatric units for bi-polar. Some have known about it prior to coming here and then stopped their medications...

There is a perception that some parents of international students with mental health conditions send their child overseas to study in order to "save face" and/or in the expectation that the Australian health care system will provide their child with the support they need.

There are certain families who either don't acknowledge mental health where they're from, or they just think we'll send him to Australia and he'll sort himself out and they ignore it. Or they might send them here because they may think the mental health services are better here than what they can get back home.

\section{Lack of social support and social isolation}

Many international students experience social isolation. Often these students will present to services with concerns about being "overwhelmed", "stressed", and "homesick". A lack of social connectedness or social exclusion is frequently behind these issues of adjustment.

I guess social connectedness is probably the big one...I just encounter on a daily basis, that it might be around isolation, or feeling not as connected as they could be.

International students were perceived to often lack the English language and social skills required to form social connections with local students.

... when students first arrive, they can often be quite unsure and not confident about their verbal language skills. So, even if our international students have good written and comprehension of English, they are often quite nervous and anxious about speaking English. That, of course, inevitably makes it more challenging for the domestic and international students to come together.

Participants feel that local students often do not put the effort into forming friendships with international students. 
...I do see a lot of domestic students almost not giving the time and energy required to foster a relationship with international students, unless really supported to do.

International students may also not relate to the 'Western/Australian' way of socialising particularly when it is centred around alcohol consumption.

I've found more so that people are saying to me, "I don't know how I am meant to socialise with people, because they tend to like going out drinking and I don't want to do that.

\section{Financial pressures}

Many international students feel pressured to financially support themselves while studying in Australia. In order to do this they must seek employment while at the same time ensuring that they do not violate their visa restrictions by working excessive hours (> 10 hours /week). This financial pressure can take a significant toll on academic performance.

I've seen a number of students over the years that have had quite significant financial difficulties, and trying to figure out how they're going to pay fees, so they don't then end up with restrictions on their enrolment or you know, they're not able to even access the facilities to be able to submit assignments, and then they get behind in their work. It's quite horrible for them to see them going through that experience, and you know, this reluctance to ask parents for any more money, because they feel as though they've already given them so much, and then trying to think about how they might work more, which could possibly put them in breach of their visa requirements and you know, it can be quite a nasty spiral for some students I think.

Often finding employment proves to be more difficult than anticipated. Given their need to financially support themselves, international students are rendered vulnerable to exploitation in the workplace.

A lot of them can get exploited, then, by businesses for cash-in-hand jobs where they get ten dollars an hour or they're not doing safe work. I've had a number of international students who have been hospitalised, because they're moped drivers for a pizza delivery paying them barely anything, and they get hit by cars and things like that too.

The financial pressures of international students were perceived to have a major impact on their mental health.

With some students, their parents may pay their fees, but, then they've got to survive the rest. So, they've got to try and seek employment, which can be difficult, to pay for their rent, pay for their living costs and so on. Other students may come from somewhere where it's not just their parents paying, it's their whole local community who are putting in for this one student to go to university overseas... There's all those types of pressures that come with it, which does lead to anxiety and depression and social isolation... 


\section{Housing}

International students often experience difficulties in finding housing that is stable, secure, safe, is not overcrowded, and is in relative proximity to their institution.

So quite often they're in really dodgy tenancy agreements. There might be 12 students living in a three bedroom place. I know we had another one recently, where there were sort of some theft and violence and what not going on in the house and they had to find accommodation really quickly.

In order to be able to afford housing, some international students live in locations that are far from campus. This impacts on their academic performance, their mental health and may put their personal safety at-risk if they are using public transportation late at night.

I can remember one student here with his wife and two children... still didn't have anywhere to live, was sleeping on the floor of different students' houses because they couldn't find accommodation. That had a huge impact on his work. I mean, he was up on charges of copying another student's work and he just said, you know, he wasn't coping....He was spending two hours in either direction to get here, didn't have the internet at home, etcetera, etcetera. So he was in a terrible position...

\section{Academic stress}

International students frequently struggle with adjusting to the expectations of the Australian educational system where skills of critical thinking may be challenging.

...the Chinese education system, the expectations are significantly different than the academic expectations of an Australian university... That can be very challenging...they go, "But I was a top student in my own country and suddenly I am either failing, or not doing academically as well”....you know, it impacts even their identity.

...I think having to come to such a different educational environment where the expectations are quite different places a huge strain on them...

In some cases, academic pressures may lead to the development of mental health issues.

So I think for international students it would be anxiety and depression. Mainly brought about because they have a lot of pressure on them from their family, and on themselves, trying to get good grades to pass, and also meet their visa requirements. So all those pressures contribute a lot to the anxiety and depression.

\section{What are the barriers to international students seeking help for their health and wellbeing problems?}

Help-seeking often occurs at crisis-point

For a variety of reasons, international students often do not seek help until health conditions, particularly mental health issues and feelings of distress, have reached crisis point. 
So unfortunately, sort of our experience, particularly with international students, is they present a little bit late. So, you know, things would have been bubbling, they might have been talking to their friends or seeking some other supports, but then sometimes we see them in the more sort of serious end of the issues that are going on, so the stress can tip over into behaviour, you know, quite severe depression and anxiety.

University supports are not designed to provide long-term support to students with severe mental health issues or complex issues. Seeing international students for the first-time at a point of crisis, puts a great deal of pressure on university services unequipped to provide the necessary support. International students are often ineligible to receive support from external community support services, putting additional pressures on university services.

I just think...to an extent when it's someone who's extremely unwell with mental health...the university supports aren't tailored to that. The most complex one I had recently was a heavy heroin and ice user, but also had a lot of trauma from sexual assault and severe mental health. A lot of it was falling onto our services. We weren't the best ones to be working with her. Our counsellors are short term...

Yeah, we do get a bit frustrated,... We're trying to manage them, but there's a lot of risk here and it simply sits with us, because you know, we're the only people that they've got, which can be quite confronting.

\section{Fear of repercussions}

Participants attribute a reluctance to attend counselling among international students to a fear that their personal information will be shared with other parties such as their faculties or their families, or they fear that their attendance at counselling will have repercussions for their visas or future employability.

So there's a bit of education required around what confidentiality and privacy means in Australia, and that we don't share things. So we do get a lot of questions about, "Will you tell the government? Will my visa be cancelled? Will you tell my parents? Who will know?" So that's still a barrier.

\section{Lack of problem recognition and understanding of health information}

Due to their cultural background, international students, may not recognise that they have a problem for which they could benefit from professional assistance.

I think that they often struggle with their own insight, so they don't understand what is going on for them, how to describe it. Therefore, they don't understand that psychological assistance would be really beneficial.

International students often lack familiarity with and understanding of Australian health services, or the relevant background to understand Australian or Western health information, which impacts on their ability to seek out the supports that could help them when they have a problem. 
... knowing about where to go to find services or programs that help them deal with those problems. So literacy in general - for international students, the health literacy might be just not being able to understand the information. So the information might be provided but they might not understand it...

\section{Cultural stigma associated with counselling}

International students may be reluctant to access counselling services because of a cultural stigma associated with mental health issues and receiving psychological support.

... I think that in our domestic environment, psychological assistance is seen as a far less threatening, concerning, stigmatised option. Whereas, I would say that for a lot of our international students, they either haven't really ever conceptualised, let alone known about it, or if they have known about it then it is still very highly, highly stigmatised.

\section{Language barriers}

Limited English-language skills were seen to be a barrier to help-seeking and accessing university supports. For example, limited English language skills limits participation in university social groups, a key way for students to connect with other students and form friendships.

.... if I was a domestic student with social isolation, compared to an international, I would say to both of them we have got social groups and things. As English is the domestic student's first language and they've grown up in Australia, they can join those groups a lot easier than international students. They don't have to worry about English as a barrier.

Limited English language skills can also be a barrier to active participation in counselling.

A lot of the language skills are based, sort of, targeted at what they are studying. So when we refer them to see counsellors, they might not grasp the idea of how counselling works. Or the language that they use in the session, might not really translate to them.

\section{What kinds of university strategies are needed to improve international students' health and wellbeing?}

Better prepare students for life in Australia through pre-departure education

International students would benefit from having more information and education about the reality of being a student in Australia. Greater discussion of the challenges they may face would allow them to prepare and plan their stay appropriately. A structured, mandatory approach to pre-departure education would ensure that all international students were better prepared for the experience of life as a student in Australia.

I think we can run some programs digitally, you know, almost like mandatory kind of programs where they need to go through it and then sign off that they read it and they understand it, you know, a slightly more structured approach rather than an unstructured approach. In my view, we should be looking at - when you start a new job in some companies, you have orientation programs that you have to clear before you get there, so something like that that you need to go through where you are actually 
confirming that you have read all that, you've gone through it and you understand it in a more structured manner...

\section{Health and wellbeing education must be integrated into all university programming}

In order to be truly effective, health and wellbeing education must be integrated with other university programs such as study support, social connection groups, or faculty programming. The best chance of success is likely to occur when rapport and trust is established prior to the introduction of health messaging.

... I just think a lot of international students don't really engage on various standalone events; but if it's integrated with study support, or one of the events, then they're more likely to take that up.

... when we come to do primary prevention we say, well, I'm going to talk to you about healthy eating, or I'm going to talk to about this or that. But that doesn't build rapport with students. That doesn't give us an 'in' to their conversation. I think some of the gap is that we need to build that rapport first. What are the things that they already enjoy doing? How can we have that engagement with them - for no other purpose, before we then start to talk about primary prevention?

\section{Education about confidentiality}

International students are often unaware of how the principles of confidentiality protect their health and wellbeing information from being shared with the government, faculties, employers, and family members. Ideally, the University should develop strategies to educate and inform international students of how their health information is protected within the University and in Australia.

There is that fear around, if I tell someone that I'm struggling it's going to impact my visa or it might impact my academic progress in some way. So I think it is about making them feel comfortable about the options that are available to them. Assuring them that there is confidential support available and that it actually will be of help in most cases.

\section{Support students to access services}

Participants feel that university health and wellbeing services are perceived as fragmented and confusing. International students require more individual support to navigate university services. Ideally, one staff member should be a key contact for students, to support them in getting the help they need and to prevent them from "falling through the cracks". Having a key staff member at a faculty level to fulfil this role was suggested.

... when a student comes in and they have this we say, "Oh, you need to talk to this person. You need to do this. You may need to do that, and then there's really no magic solution, but those are the things that you need to do." Now, for people with high functioning levels, at the best of times they might be able to follow those things. I think what we really need to do is take some of that responsibility and say, "Well, actually it's hard for you to navigate the system. We know the system. But we're not going to let hang you dry and get you to figure out this system. So we're going to facilitate this system. 
I think we need to make it easier for students... if we're expecting students to go out and seek the service, they won't. We really have got to focus on bringing the service to them... I think it's important for us to get those support services into the faculties.

\section{After-hours and online mental health support}

International students sometimes require mental health support outside of 9 to 5 hours and currently, the University does not offer any after-hours support. It was suggested that the university could look at providing online or telephone support to students outside of hours to complement counselling helplines available to the general public.

...international students want to be able to talk to somebody and they want to be able to talk to somebody after hours... [we] should be providing an after-hours sort of phone, online stuff.

...I think a lot of international students do use online services, and they like to use that...Just having that initial contact online, I guess it can put them at ease, to access a service in person, and be more aware of the service. Online, it's more anonymous I guess, and at the start they don't have to be face-to-face, and they can just build that confidence to be able to initially talk about it.

Need for greater communication between faculties and health and wellbeing services

Some staff concerned about international students waiting too long to seek help suggested that academic or professional staff might effectively refer them to counselling or medical services.

If the faculties are away and monitoring outcomes and then highlighting that the students are not coping or are not performing as they would be expected to, it would be helpful if faculties highlighted those things at an earlier stage. Rather than wait for the student to come when they've failed the whole semester, and then there's all this pressure on how to fix it at this point. Whereas, if it had been picked up earlier then one could intervene.

... we [health service] don't come on the radar until the proverbial has hit the fan. They come at crisis, and I think what we're trying to impart is the fact that we'd like to see them before the crisis, so that we can intervene or help redirect them or support them.... They [faculties] see us as the fix it people. I think that's not okay.

While well-intentioned, this would assume academic and professional staff can distinguish mental health problems from academic difficulties, and raises potential concerns about the appropriateness of sharing health information between faculties and health services (see perceived student concerns about confidentiality above).

\section{Skills building to promote social connection}

International students would benefit from learning about Australian social norms, and from being supported to further develop their English language skills in social contexts. 
So it would be, you know, your general sort of information around how to make friends, because we've got to also think that if somebody has come directly from their home country where they've perhaps gone through their entire lower and higher school education with the same group of friends, they haven't had to make friends for many, many, many years and they sort of forget how they did that when they were so young. So teaching them that they do have those skills and building their confidence in that, building their confidence around their language, you know, their skills with English language can be really helpful.

\section{Discussion}

This study explored the challenges and opportunities for improving the health and wellbeing of international students through interviews with university professional staff providing support services to international students. According to participants, mental health was by far the most significant health and wellbeing concern for international students. Social isolation, financial pressures, housing/accommodation concerns, and academic stressors were also seen as significant health and wellbeing concerns impacting on students' mental health. A number of help-seeking barriers were also identified, including fear of repercussions, lack of problem recognition and understanding of health information, cultural stigma associated with counselling, and language barriers. A tendency to delay help-seeking until problems reach a crisis-point was a particular concern. Participants also made a number of suggestions of strategies for improving the health and wellbeing of international students, which are discussed below.

Mental health stood out as the main health and wellbeing concern for international students. Participants reported mental health concerns ranging from stress, anxiety, and depression through to complex psychiatric conditions. This is consistent with a growing body of research revealing high prevalence of mental health problems among university/college students in general. Recent crossnational studies of both local and international students studying in a range of countries, including Australia, have found 12-month mental disorder prevalence rates to range from $20 \%$ to $45 \%$ (Auerbach et al., 2016; Auerbach, Mortier, Bruffaerts, Alonso, Benjet, Cuijpers, Demyttenaere, Ebert, Green, Hasking, Murray, et al., 2018; Blanco et al., 2008), with anxiety, mood, and substance use disorders the most widespread (Auerbach et al., 2016). Our interviewees also suggested that international students sometimes come to Australia with pre-existing psychological/psychiatric conditions. In some instances students may not have received an official diagnosis or adequate treatment in their home country. Symptoms or behaviours of concern may emerge due to the stress of adjusting to a new environment, lack of support from their usual social network, or changes to the management of their condition (i.e. discontinuing their psychotropic medications prior to or after arriving in Australia). This is consistent with the findings of Forbes-Mewett and Sawyer (2016) who reported concerns about the increasing number of international students with pre-existing psychiatric disorders. Staff felt that greater scrutiny of such international students was warranted in order to assess their ability to cope with studying overseas (Forbes-Mewett \& Sawyer, 2016). In the current study, participants reported that they found it challenging to assist these students with the limited tools available to them. Participants often have limited knowledge of a student's mental health history and, in cases of complex or severe mental health issues requiring psychiatric hospitalisation, students' families may be reluctant to engage with University staff on this issue.

Interestingly, other reported health and wellbeing issues identified by participants are not stand-alone concerns but have direct influences on students' mental health. A lack of social support and social isolation were seen as significant issues, echoing findings of previous studies (Arkoudis et al., 2019; Sawir et al., 2008; Skromanis et al., 2018; Townsend \& Poh, 2008). Students' lack of a strong social networks and connections often resulted in loneliness and homesickness, which negatively impacts on students' mental health. International students were perceived to come to Australia with a sincere desire to form friendships, particularly with Australian students, however, for many, this expectation 
is often not met. This finding is in line with previous studies highlighting international students' desire to form social connections with local students and local community members (Arkoudis et al., 2019; Ryan et al., 2016; Sawir et al., 2008; Sherry et al., 2010; Townsend \& Poh, 2008; TummalaNarra \& Claudius, 2013; Zhang \& Brunton, 2007). However, research also shows that international students are more likely to seek support and advice from other international students and perceive that they receive greater socioemotional and instrumental support from international students than local students (Chavajay, 2013; Misra et al., 2003; Poyrazli et al., 2004).

As suggested by our participants, limited English language skills may be a barrier to students forming friendships and social connections, particularly with local students (Forbes-Mewett \& Sawyer, 2016; Mori, 2000; Poyrazli et al., 2002). Forming social connections in the local community is especially important for international students' sociocultural adjustment. A systematic review of the predictors of psychosocial adjustment of international undergraduate and graduate students in the United States found that social contact with Americans (e.g. friendship and frequency of conversations) was one of the most frequently reported predictors of sociocultural adjustment (Zhang \& Goodson, 2011). This review also found social support to be the second most frequently reported predictor of psychological symptoms among international students, highlighting the importance of social support and social connection to the emotional wellbeing of international students (Zhang \& Goodson, 2011).

Many international students were perceived to be experiencing financial difficulties, which may lead to anxiety, depression and distress. Students seeking employment in Australia may struggle to balance finding and maintaining employment while maintaining satisfactory academic performance. Previous studies have also found that, contrary to the stereotype of the 'wealthy overseas student', many international students experience significant financial distress during their time abroad (Arkoudis et al., 2019; Forbes-Mewett \& Sawyer, 2016; Poyrazli \& Grahame, 2007; Roberts et al., 1999; Ryan et al., 2016).

Participants in our study reported that international students often have difficulty in sourcing stable, safe housing that is within reasonable proximity to the university and is not overcrowded. These housing stressors may compromise students' academic performance and negatively impact on their mental health. Previous research exploring the experiences of international students living and studying in Sydney also found that finding suitable, clean housing was difficult for many students and impacted on their wellbeing and their overall experience of studying in Australia (Ryan et al., 2016).

For many international students, adapting to and meeting the academic standards of the Australian education system was seen as a particular struggle. The resulting academic pressures students experience and the expectations that come, from themselves and their families, can lead to mental health problems such as anxiety and depression. Students often expect to be able to perform academically at the same level as they did in their country of origin, and may be shocked when a culturally different learning and teaching system, as well as the requisite English language skills, make this more difficult than anticipated. This finding is in line with previous research showing difficulties adjusting to Western learning styles or language barriers impact on students' academic performance and overall University experience (Bird, 2017; Cao et al., 2018; Forbes-Mewett \& Sawyer, 2016; Kingston \& Forland, 2008; Li et al., 2009; Poyrazli \& Kavanaugh, 2006; Yan \& Berliner, 2009). These difficulties, in addition to expectations that students' academic performance will be the same or better than it was in their home country as well as family pressures to maintain academic performance, in turn decreased confidence and result in poorer adaptation to the new environment (Chen, 1999).

Participants highlighted a number of barriers to international students seeking assistance for their health and wellbeing problems. One of the greatest difficulties reported was that international students frequently delay help-seeking, particularly for mental health problems, until their problem has reached crisis point. This is in line with previous Australian research (Forbes-Mewett \& Sawyer, 
2016). In the current study, delays in seeking help from early onset of symptoms severely compromised participants' ability to provide effective assistance to these students. Like University staff in the Forbes-Mewett and Sawyer (2016) study, participants in our study felt that the short-term nature of university support services meant that both staff and available services were ill-equipped to adequately manage the often complex cases that presented. Participants suggested a number of strategies to address this. Firstly, some believed that greater communication between faculties and health services could be beneficial, with faculties 'flagging' students whose academic performance is substantially dropping to medical and counselling services. While this might allow these students to be targeted for early intervention, it conflicts with privacy and confidentiality concerns around medical information being shared across the university. Further, it would not be appropriate to assume that every student struggling academically is also experiencing mental health problems warranting professional services. Academic and professional staff, unless it is an emergency situation (e.g., expressing suicidal thoughts), are not authorised nor necessarily qualified to refer people to medical services. A resolution would be to provide training to university staff on how to recognise possible mental health problems and how to suggest sources of appropriate support or professional help (e.g., mental health literacy or mental health first aid training). In instances where students consent to assistance with help-seeking, university staff could then assist the student in obtaining professional help.

Secondly, participants felt that international students would benefit from the availability of afterhours support, particularly for mental health. While staff were aware of after-hours community-based telephone supports, they would like to see online or telephone support provided by the university. This could have several benefits. It would help to alleviate some of the burden placed on campus medical and counselling services during standard working hours and would ensure that students can access support in their time of need. While research has shown that international students studying in Australia have a preference for mental health treatment delivered face-to-face; many are also open to engaging in online mental health treatments (Lu et al., 2014). As reported by participants in this study and highlighted in previous research (Ang \& Liamputtong, 2008; Lu et al., 2014; Nilsson et al., 2004), limited English language skills and stigma associated with seeking mental health assistance may prevent some students from accessing or persisting with face-to-face counselling. For these students, online mental health support may be a more comfortable and acceptable option.

Another significant barrier to international students accessing help, particularly for mental health problems, was a fear of repercussions. Like the concerns raised in the Forbes-Mewett and Sawyer study (2016), participants in our research felt that international students may be hesitant to seek psychological assistance for fear of having to reveal personal information. Participants felt that students harbour particular concerns that this information will be passed on to faculties, family members, or may be recorded on their academic transcript. Students may also fear that this information will place their visa in jeopardy. International students are often unaware of confidentiality policies that govern and protect students' health and wellbeing information. Ideally, participants would like to see the university develop clear strategies to educate and inform international students of how their personal health information will be protected and handled within the university.

Many international students are perceived to possess low levels of western or Australian health literacy. Similarly to previous research ( $\mathrm{Lu}$ et al., 2014), students often lack the skills and understanding to recognise what would be considered a mental health problem in Australia. This is a particular problem as research has shown that an inability to identify the need for treatment despite acknowledging symptoms predicts low rates of treatment seeking for emotional problems among university students in general (Eisenberg et al., 2007). In a similar vein, participants in our study felt that international students often lack familiarity with Australian health services or the skills to be able to interpret health information provided to them. In tackling this problem, education was seen as key. 
Currently, health messaging is often delivered at 'one-off' events or forums. In order to be more effective, participants suggested that health education should be integrated into ongoing university programs such as study support, social connection groups, or faculty programs. In programs where trust and rapport is already established, health education is more likely to be accepted and understood. Educational content should ideally provide students with the knowledge and skills needed to identify when they are in need of support, particularly for mental health. Such psychoeducation or mental health literacy training would also aim to 'de-mystify' and de-stigmatise the nature of psychological assistance; framing counselling supports as a preventive resource. Ideally, the education of international students should begin before students leave their home country through mandatory predeparture education which could include a health/mental health component.

International students find the structure of university support services to be both confusing and fragmented, making it difficult to obtain support in times of need. Previous Australian research has similarly highlighted that international students' limited knowledge of available services as well as difficulties navigating a "culturally different heath system" are barriers to students accessing mental health support (Forbes-Mewett \& Sawyer, 2016; Lu et al., 2014). Participants in our study felt that international students would benefit from continued education focussed on raising awareness of the kinds of health and wellbeing supports available at the university. A further suggestion was that international students would benefit from more personalised assistance to navigate university support services. It was suggested that there should be a member of staff, ideally within each Faculty, who is a 'key contact' for international students. The primary purpose of this staff member's role would be to direct and support students to get the health and wellbeing assistance they need and prevent them from 'falling through the cracks'.

There are several limitations to this research that should be noted. Firstly, our sample size of 25 professional university staff is not representative and participant roles were not inclusive of all roles supporting the health and wellbeing of international students within the University. Secondly, participants were all from one Australian University. Therefore, it cannot be assumed that the results of this study will generalise to other Universities or to other host countries as the socio-demographic and cultural diversity of international students will naturally vary between educational environments and settings. Finally, this research was conducted prior to COVID. The tertiary sector has been heavily impacted by COVID and this will undoubtedly have an impact on the experience of international students for many years to come. Despite these limitations, we have noted much consistency between the findings of our study and the findings of prior research.

\section{Conclusions}

This study explored the challenges and opportunities for improving the health and wellbeing of international students based on in-depth interviews with 25 health and student services staff at an Australian University. Our findings highlight the key health and wellbeing issues for international students, illuminate the barriers to international students accessing campus-based services for health and wellbeing concerns, and provide suggested strategies to improve the health and wellbeing of international students. It is hoped that these findings go some way towards contributing to an evidence base of information that can be used to inform and further develop university service delivery for international students and may assist in attracting international students back to Australia postCOVID. 


\section{References}

Alonso, J., Vilagut, G., Mortier, P., Auerbach, R. P., Bruffaerts, R., Cuijpers, P., Demyttenaere, K., Ebert, D. D., Ennis, E., Gutiérrez-García, R. A., Green, J. G., Hasking, P., Lee, S., Bantjes, J., Nock, M. K., Pinder-Amaker, S., Sampson, N. A., Zaslavsky, A. M., \& Kessler, R. C. (2018). The role impairment associated with mental disorder risk profiles in the WHO world mental health international college student initiative. International Journal of Methods in Psychiatric Research. https://doi.org/10.1002/mpr.1750

Ang, P. L. D., \& Liamputtong, P. (2008). "Out of the circle": International students and the use of university counselling services. Australian Journal of Adult Learning, 48, 108-130.

Arkoudis, S., Dollinger, M., Baik, C., \& Patience, A. (2019). International students' experience in Australian higher education: can we do better? Higher Education, 77, 799-813.

Auerbach, R. P., Alonso, J., Axinn, W. G., Cuijpers, P., Ebert, D. D., Green, J. G., ., \& Bruffaerts, R. (2016). Mental disorders among college students in the World Health Organization World Mental Health Surveys. Psychological Medicine, 46(14), 2955-2970. https://doi.org/https://doi.org/10.1017/s0033291716001665 (Editor's note: a correction has been issued for this article see: Auerbach RP, Alonso J, Axinn WG, Cuijpers P, Ebert DD, Green JG, Hwang I, Kessler RC, Liu H, Mortier P, Nock MK, Pinder-Amaker S, Sampson NA, Aguilar-Gaxiola S, Al-Hamzawi A, Andrade LH, Benjet C, Caldas-de-Almeida JM, Demyttenaere K, Florescu S, de Girolamo G, Gureje O, Haro JM, Karam EG, Kiejna A, Kovess-Masfety V, Lee S, McGrath JJ, O'Neill S, Pennell BE, Scott K, Ten Have M, Torres Y, Zaslavsky AM, Zarkov Z, Bruffaerts R. Mental disorders among college students in the World Health Organization World Mental Health Surveys. Psychol Med. 2016 Oct;46(14):2955-2970. doi: 10.1017/S0033291716001665. Epub 2016 Aug 3. Erratum in: Psychol Med. 2017 Nov;47(15):2737. PMID: 27484622; PMCID: PMC5129654.)

Auerbach, R. P., Mortier, P., Bruffaerts, R., Alonso, J., Benjet, C., Cuijpers, P., Demyttenaere, K., Ebert, D. D., Green, J. G., Hasking, P., Lee, S., Lochner, C., McLafferty, M., Nock, M. K., Petukhova, M. V., Pinder-Amaker, S., Rosellini, A. J., Sampson, N. A., Vilagut, G., Zaslavsky, A. M., \& Kessler, R. C. (2018). Mental disorder comorbidity and suicidal thoughts and behaviors in the world health organization world mental health surveys international college student initiative. International Journal of Methods in Psychiatric Research. https://doi.org/10.1002/mpr.1752

Auerbach, R. P., Mortier, P., Bruffaerts, R., Alonso, J., Benjet, C., Cuijpers, P., Demyttenaere, K., Ebert, D. D., Green, J. G., Hasking, P., Murray, E., Nock, M. K., Pinder-Amaker, S., Sampson, N. A., Stein, D. J., Vilagut, G., Zaslavsky, A. M., \& Kessler, R. C. (2018). WHO World Mental Health Surveys International College Student Project: Prevalence and distribution of mental disorders. Journal of Abnormal Psychology, 127(7), 623-638. https://doi.org/10.1037/abn0000362

Bird, E. L. (2017). Student and staff perceptions of the international postgraduate student experience: a qualitative study of a UK University. Journal of International Students, 7(2), 329-346.

Blackmore, J., Gribble, C., \& Rahimi, M. (2017). International education, the formation of capital and graduate employment: Chinese accounting graduates' experiences of the Australian labour market. Critical Studies in Education, 58(1), 69-88.

Blanco, C., Okuda, M., Wright, C., Hasin, D. S., Grant, B. F., Liu, S. M., \& Olfson, M. (2008). Mental health of college students and their non- college-attending peers. Archives of General Psychiatry, 65(12). https://doi.org/https://doi.org/10.1001/archpsyc.65.12.1429-1437.

Cao, C., Zhu, C., \& Meng, Q. (2018). Chinese international students' coping strategies, social support resources in response to academic stressors: Does heritage culture or host context matter? Current Psychology: A Journal for Diverse Perspectives on Diverse Psychological Issues. https://doi.org/10.1007/s12144-018-9929-0

Carlson, P., Browne, V., \& Changkaoprom, A. (2020). Update on the development of the Australian University mental health framework. Journal of the Australian and New Zealand Student Services Association, 28(1), 40-45.

Chavajay, P. (2013). Perceived social support among international students at a US University. Psychological Reports, 112(2), 667-677. https://doi.org/10.2466/17.21.PR0.112.2.667-677

Chen, C. P. (1999). Common stressors among international college students: Research and counseling implications. Journal of College Counseling, 2(2), 49-65.

Coroners Court of Victoria. (2019). Finding into death without inquest: COR 2016 1035. Retrieved 30th July 2019 from https://www.coronerscourt.vic.gov.au/sites/default/files/2019-01/16\%201035.pdf 
Cuijpers, P., Auerbach, R. P., Benjet, C., Bruffaerts, R., Ebert, D., Karyotaki, E., \& Kessler, R. C. (2019). Introduction to the special issue: The who world mental health international college student (wmh-ics) initiative. International Journal of Methods in Psychiatric Research. https://doi.org/10.1002/mpr.1762

Department of Education and Training. (2015). International student survey 2014 overview report. Department of Education and Training, Australian Government. https://internationaleducation.gov.au/research/researchpapers/Documents/ISS\%202014\%20Report\%20Final.pdf

Department of Education and Training. (2017). Higher education standards panel final report - improving retention, completion and success in higher education (Higher Education Standards Panel, Issue. https://docs.education.gov.au/node/50816

Department of Education and Training. (2019a). 2018 export income by State and Territory. Australian Government. Retrieved 24th June from https://internationaleducation.gov.au/research/Research-Snapshots/Documents/ Education\%20infographic\%20Australia\%202018.pdf

Department of Education and Training. (2019b). 2018 International Student Survey Results. Australian Government. Retrieved 24th June from https://internationaleducation.gov.au/research/research-papers/Documents/ED190079\%20-\%20INT\%20-\%202018\%20International\%20Student\%20Survey\%20$\% 20$ Headline\%20findings\%20-\%20update_02.pdf

Department of Education and Training. (2019c). Education export income by country 2018. Australian Government. Retrieved 24th June from https://internationaleducation.gov.au/research/Research-Snapshots/Documents/ Education\%20infographic\%20Australia\%202018.pdf

Department of Education and Training. (2019d). International Student Data Monthly Summary. Australian Government. Retrieved 24th June from https://internationaleducation.gov.au/research/International-Student-Data/ Documents/MONTHLY\%20SUMMARIES/2019/Apr\%202019\%20MonthlyInfographic.pdf

Ebert, D. D., Franke, M., Kählke, F., Küchler, A. M., Bruffaerts, R., Mortier, P., Karyotaki, E., Alonso, J., Cuijpers, P., Berking, M., Auerbach, R. P., Kessler, R. C., \& Baumeister, H. (2018). Increasing intentions to use mental health services among university students Results of a pilot randomized controlled trial within the world health organization's world mental health international college student initiative. International Journal of Methods in Psychiatric Research. https://doi.org/10.1002/mpr.1754

Ebert, D. D., Mortier, P., Kaehlke, F., Bruffaerts, R., Baumeister, H., Auerbach, R. P., Alonso, J., Vilagut, G., Martínez, K. U., Lochner, C., Cuijpers, P., Kuechler, A. M., Green, J., Hasking, P., Lapsley, C., Sampson, N. A., \& Kessler, R. C. (2019). Barriers of mental health treatment utilization among first-year college students: First crossnational results from the who world mental health international college student initiative. International Journal of Methods in Psychiatric Research. https://doi.org/10.1002/mpr.1782

Eisenberg, D., Golberstein, E., \& Gollust, S. E. (2007). Help-seeking and access to mental health care in a university student population. Medical Care, 45(7), 594-601.

Forbes-Mewett, H., \& Sawyer, A. (2011, November 29-December 2). Mental health issues amongst international students in Australia: perspectives from professionals at the coal-face. The Australian Sociological Association Conference Local lives/Global networks, University of Newcastle, NSW.

Forbes-Mewett, H., \& Sawyer, A. (2016). International students and mental health. Journal of International Students, 6(3), 661-677.

Gribble, C. (2014). Employment, work placements \& work integrated learning of international students in Australia (Research Digest, Issue. https://www.ieaa.org.au/documents/item/257

Hyun, J., Quinn, B., Madon, T., \& Lustig, S. (2007). Mental health need, awareness, and use of counseling services among international graduate students. Journal of American College Health, 56(2), 109-118.

Kingston, E., \& Forland, H. (2008). Bridging the gap in expectations between international students and academic staff. Journal of Studies in International Education, 129(2), 204-221.

Li, G., Chen, W., \& Duanmu, J. (2009). Determinants of international Students' academic performance: A comparison between Chinese and other international students. Journal of Studies in International Education, 14(4), 389-405. https://doi.org/https://doi.org/10.1177/

Lu, S. H., Farran Dear, B., Johnston, L., Wootton, B., \& Titov, N. (2014). An internet survey of emotional health, treatment seeking and barriers to accessing mental health treatment among Chinese-speaking international students in Australia. Counselling Psychology Quarterly, 27(1), 96-108.

https://doi.org/10.1080/09515070.2013.824408 
Marginson, S. (2018). The UK in the global student market: second place for how much longer? Centre for Global Higher Education. https://www.researchcghe.org/publications/research-findings/the-uk-in-the-global-student-marketsecond-place-for-how-much-longer/

Misra, R., Crist, M., \& Burant, C. J. (2003). Relationships among life stress, social support, academic stressors, and reactions to stressors of international students in the United States. International Journal of Stress Management, 2, 137-157.

Mori, S. (2000). Addressing the mental health concerns of international students. Journal of Counseling and Development, 78(137-144).

Nilsson, J., Berkel, L., Flores, L., \& Lucas, M. (2004). Utilization rate and presenting concerns of international students at a university counseling centre. Journal of College Student Psychotherapy, 19(2), 49-59.

Poyrazli, S., Arbona, C., Nora, A., McPherson, R., \& Pisecco, S. (2002). Relation between assertiveness, academic selfefficacy, and psychosocial adjustment among international graduate students. Journal of College Student Development, 43, 632-642.

Poyrazli, S., \& Grahame, K. M. (2007). Barriers to adjustment: Needs of international students within a semi-urban campus community. Journal of Instructional Psychology, 34, 28-45.

Poyrazli, S., \& Kavanaugh, P. R. (2006). Marital status, ethnicity, academic achievement, and adjustment strains: The case of graduate international students. College Student Journal, 40, 767-780.

Poyrazli, S., Kavanaugh, P. R., Baker, A., \& Al-Timimi, N. (2004). Social support and demographic correlates of acculturative stress in international students. Journal of College Counseling, 7, 73-82.

Redfern, K. (2016). An empirical investigation of the incidence of negative psychological symptoms among Chinese international students at an Australian university. Australian Journal of Psychology, 68(4), 281-289. https://doi.org/doi.org/10.1111/ajpy.12106

Roberts, R., Golding, J., Towell, T., \& Weinreib, I. (1999). The effects of economic circumstances on British students' mental and physical health. Journal of American College Health, 48, 103-109.

Rosenthal, D. A., Russell, V., \& Thomson, G. D. (2006). A growing experience: the health and well-being of international students at the University of Melbourne. https://services.unimelb.edu.au/_data/assets/ pdf_file/0011/358436/GrowingExperience.pdf

Ryan, M. L., Shochet, I. M., \& Stallman, H. M. (2010). Universal online interventions might engage psychologically distressed university students who are unlikely to seek formal help. Advances in Mental Health, 9, 73-83.

Ryan, R., Dowler, B., Bruce, S., Gamage, S., \& Morris, A. (2016). The wellbeing of international students in the City of Sydney. Institute for Public Policy and Governance Sydney. https://www.cityofsydney.nsw.gov.au /_data/assets/pdf_file/0005/277682/Research-into-the-Wellbeing-of-International-Students-in-the-City-ofSydney_Final_27-July-2016.pdf

Sawir, E., Marginson, S., Deumert, A., Nyland, C., \& Ramia, G. (2008). Loneliness and international students: An Australian study. Journal of Studies in International Education, 12, 148-180.

Sherry, M., Thomas, P., \& Chui, W. H. (2010). International students: A vulnerable student population. . Higher Education, 60(1), 33-46.

Skeat, J. (2010). Using grounded theory in health research. In P. Liamputtong (Ed.), Research Methods in Health: Foundations for Evidence-Based Practice (pp. 106-122). Oxford University Press.

Skromanis, S., Cooling, N., Rodgers, B., Purton, T., Fan, F., Bridgman, H., Harris, K., Presser, J., \& Mond, J. (2018). Health and well-being of international university students, and comparison with domestic students, in Tasmania, Australia. International Journal of Environmental Research and Public Health, 15, 1147. https://doi.org/10.3390/ijerph15061147.

Townsend, P., \& Poh, H. J. (2008). An exploratory study of international students studying and living in a regional area. Journal of Marketing for Higher Education, 18, 240-263.

Tummala-Narra, P., \& Claudius, M. (2013). A qualitative examination of Muslim graduate international students' experiences in the United States. International Perspectives in Psychology: Research, Practice, Consultation, 2(2), 132-147. https://doi.org/10.1037/ipp0000003

Yan, K., \& Berliner, D. C. (2009). Chinese international students' academic stressors in the United States. College Student Journal, 43(3), 939-960. 
Zhang, J., \& Goodson, P. (2011). Predictors of international students' psychosocial adjustment to life in the United States: A systematic review. International Journal of Intercultural Relations, 35(2), 139-162. https://doi.org/10.1016/j.ijintrel.2010.11.011

Zhang, Z., \& Brunton, M. (2007). Differences in living and learning: Chinese international students in New Zealand. Journal of Studies in International Education, 11, 124-140.

The authors may be contacted via

danielle.newton@deakin.edu.au

\section{Please cite this paper as:}

Newton, D.C., Tomyn, A.J., \& LaMontagne, A.D. (2021). Exploring the challenges and opportunities for improving the health and wellbeing of international students: Perspectives of professional staff at an Australian University. Journal of the Australian and New Zealand Student Services Association, 29(1), 74-92. https://doi.org.10.30688/janzssa.2021.1.01 